\title{
As vicissitudes das ciências humanas, de Merleau-Ponty a Foucault
}

\author{
Salma Tannus Muchail \\ Pontifícia Universidade Católica de São Paulo - PUC-SP
}

\section{RESUMO}

Estudiosos de Maurice Merleau-Ponty e de Michel Foucault estabelecem pontos de aproximação entre ambos, sem negação de suas diferenças. $\mathrm{O}$ presente ensaio indica alguns aspectos selecionados nos dois autores na direção de reforçar estes pontos.

\section{PALAVRAS-CHAVE}

Ciências humanas; Configuração; História.

\begin{abstract}
The scholarship on Maurice Merleau-Ponty and Michel Foucault established points of approximation between those authors, without denying their differences. The present essay indicates some aspects selected by both authors in order to reinforce some of these points.
\end{abstract}

\section{KEY WORDS}

Human sciences; Configuration; History. 


\section{Crise conjuntural ou peculiaridade estrutural?}

As chamadas ciências humanas são talvez o tema mais fundamental, solo dos demais, a receber a atenção de Merleau-Ponty e de Foucault.

Sáo conhecidos os muitos estudos de Merleau-Ponty que, dedicados às ciências humanas, descrevem uma certa crise que as afetaria desde seu surgimento. Segundo ele, esta crise não chega a constituir uma questáo polêmica nem mesmo teórica. Afinal, não se trata de "um problema de escola que só se colocaria em função das teses ou das opiniōes de uma determinada tendência filosófica" (Merleau-Ponty, 1973, p. 15). Trata-se, ao contrário, de uma situação de fato decorrente do próprio desenvolvimento das ciências humanas. Com efeito, com o recurso de instrumentos objetivos, laboratoriais, estatísticos, seus resultados trazem à luz a existência de condicionamentos que afetariam todo pensamento e todo saber: são condicionamentos psicológicos, sociológicos, históricos, etc. que, como que do exterior, põem em questão a integridade do saber filosófico, mas também delas próprias, as ciências humanas. Como confiar nas filosofias e nos saberes positivos, todos eles psicológica, sociológica e historicamente condicionados? Em consequência, a psicologia tende a tudo psicologizar, a sociologia a sociologizar, a história a historicizar, redundando em posiçóes unilaterais ou sectárias conhecidas como "psicologismo", "sociologismo" ou "historicismo". "Ora, com isto", escreve Merleau-Ponty, "elas acabavam por erradicar seus próprios fundamentos" (Ibid., p. 16). Para que possam enfrentar seu complexo objeto que simultaneamente é sujeito, precisam buscar procedimentos metodológicos específicos (assim como a física de Galileu encontrou para seus objetos próprios, como já dissera Husserl), isto é, adequados a este sujeito que é também objeto. Nesta busca, precisam municiar-se através do intercâmbio com o pensamento filosófico sobre o homem, de modo a que se estabeleça uma correlação recíproca em que a filosofia, por seu turno, também se abastecerá com as contribuiçóes das investigaçóes científicas. Precisam encontrar e deixar que se mostre aquilo que Merleau-Ponty chamará de o metafísico no homem (Merleau-Ponty, 1980). Crise, portanto - da filosofia e das ciências humanas - mas sempre crise, isto é, episódica, factual, conjuntural.

Quando Foucault se propóe a construir sua arqueologia das ciências humanas, não é uma crise o que encontra. Aquilo que fora descrito como contingencial, é agora diagnosticado como necessário, teoricamente originário, uma espécie de peculiaridade estrutural. Historicamente datado (fins do século XIX e início do século XX), o nascimento das ciências humanas é gerado no acoplamento de duas vertentes que se complementam e as situam: por um lado, nos interstícios de três dimensóes ou categorias modernas - a vida, o trabalho, a linguagem - que, na mesma época, passam a constituir objetos na ordem dos saberes empíricos (a biologia, a economia, a 
filologia); por outro lado, na intersecção destas dimensóes positivas com categorias filosóficas da modernidade (a concepção do homem como duplo empírico-transcendental e, por isto, passível de constituir-se como sujeito e como objeto de conhecimento, o resgate do corpo na conjunção com o cogito, a descoberta, enfim, da finitude). Circunscritas às condiçôes de seu surgimento, as ciências humanas não têm vocação a um estatuto especificamente científico que eventualmente atravessasse alguma crise a ser supostamente superada. Ao contrário, não há que romper a estrutura que lhes é congênita. A situação (ou a epistemê) que as torna possíveis atribui-lhes, necessariamente, uma "instabilidade essencial" (Foucault, 1981, p. 365).

Portanto, perspectivas diferentes sobre preocupaçóes comuns. Mas, os riscos a que, na descrição de Merleau-Ponty, as ciências humanas podem conduzir, são semelhantes aos que Foucault aponta, isto é, aqueles sectarismos psicológicos, sociológicos, históricos, etc. em razão, precisamente da sua "irredutível precariedade" epistemológica (Ibid.).

Uma síntese destas preocupaçôes e perspectivas pode ser lida na reprodução de duas passagens de Foucault.

O que explica a dificuldade das 'ciências humanas' (sempre entre aspas), sua precariedade, sua incerteza como ciências, sua perigosa familiaridade com a filosofia, seu apoio mal definido sobre outros domínios do saber, seu caráter sempre secundário e derivado, como também sua pretensão ao universal, não é, como frequentemente se diz, a extrema densidade de seu objeto; não é o estatuto metafísico ou a indestrutível transcendência desse homem de que elas falam, mas, antes, a complexidade da configuração epistemológica onde se acham colocadas. (Ibid., p. 365)

E, mais adiante,

Inútil, pois, dizer que as 'ciências humanas' (sempre entre aspas) são falsas ciências; a configuraçáo que define sua positividade e as enraíza na epistemê moderna coloca-as, ao mesmo tempo, fora da situaçáo de serem ciências; e se se perguntar então porque assumiram esse título, bastará lembrar que pertence à definição arqueológica de seu enraizamento o fato de que elas requerem e acolhem a transferência de modelos tomados de empréstimo às ciências. Não é, pois, a irredutibilidade do homem, aquilo que se designa como sua invencível transcendência nem mesmo sua complexidade demasiado grande que o impede de tornar-se objeto de ciência. A cultura ocidental constituiu, sob o nome de homem, um ser que, por um único e mesmo jogo de razóes, deve ser domínio positivo do saber e não pode ser objeto de ciência. (Ibid., p. 383-384)

Destas passagens, depreendem-se elementos de semelhanças e de diferenças.

Primeiro, a referência à compreensão fenomenológica e particularmente merleau-pontiana das relaçóes entre a filosofia e as ciências humanas; e aqui, o 
distanciamento foucaultiano relativamente a um essencial estatuto metafísico do homem, como suposta base destas relaçóes.

Segundo, a afirmação de que as ciências humanas "requerem e acolhem a transferência de modelos tomados de empréstimo às ciências"; e aqui, a proximidade de Foucault com a crítica merleau-pontiana de que seria necessário às ciências humanas municiarem-se de procedimentos metodológicos que lhes fossem apropriados.

Terceiro, de modo muito particular, o uso da noção de configuração, presente nas duas passagens citadas: "configuração epistemológica onde (as ciências humanas) se acham colocadas"; "configuração que define sua positividade e as enraíza na epistemê moderna"; e aqui, aproximando mais os dois pensadores, a ideia de que aquela "irredutível precariedade" epistemológica das ciências humanas não significa que elas sejam "falsas ciências", ou "uma impostura" ou meros "fenômenos de opiniáo" (Ibid., p. 382); significa que são outros saberes, ou melhor, outras configuraçôes do saber (Ibid., p. 383).

Finalmente e de modo mais geral, a atribuição, por Foucault, da noção de saber às ciências humanas; e aqui, mais ampla que a de ciência, a noção de saber permite conduzir o pensamento de Merleau-Ponty, a partir de Foucault, como que às suas últimas consequências.

O destaque destes elementos remete à consideração de outro paralelo.

\section{Proximidade de noções}

Um dos mais cuidadosos e instrutivos estudos sobre aproximaçóes entre MerleauPonty e Foucault é o livro de Judith Revel, Foucault avec Merleau-Ponty-ontologie politique, présentisme et histoire (Revel, 2015). Está organizado em duas partes (precedidas de uma Introdução e sucedidas de uma Conclusão), cada qual composta por três capítulos, a primeira delas dedicada a Foucault e a segunda a Merleau-Ponty. Ao longo de todo o livro observa-se a recorrência de termos ou expressóes que remetem tanto ao pensamento de um quanto ao do outro, veiculando posiçóes partilhadas por ambos. Entre elas, uma das mais frequentes, é justamente a de configuração. Aparece já no primeiro parágrafo da Introdução, como uma interrogação:

O que é que, em um dado momento, torna possível que uma coisa, um conceito, um objeto, uma prática, uma experiência, uma forma de relaçáo de si aos outros, pouco importa, sejam pensados sob uma certa configuração? Quais são as condições históricas de emergência da maneira pela qual, em um dado momento, pensamos o mundo e nós mesmos no seio deste mundo? (Revel, 2015, p. 7)

O sentido de configuração como "condições históricas" tem semelhança com certas expressóes usadas por Merleau-Ponty, como, por exemplo (para citar um só 
texto), "espírito de uma civilização" ou "espírito de uma sociedade" (MerleauPonty, 1980, p. 184-185).

No segundo parágrafo, a noção é remetida mais especificamente ao vocabulário de Foucault:

Esta questão é muito precisamente aquela que Michel Foucault tenta construir desde seus primeiros trabalhos [...]; é o fato de fazer da filosofia, em um retorno do pensamento sobre sua própria história, um exercício de arqueologia que faz ver não somente a gramática de nossa apreensão do mundo, mas também [...] as partilhas que definem para cada época o espaço ao mesmo tempo homogêneo e disparate daquilo que Foucault chamava uma epistemê [...]; para ele, a filosofia será doravante o nome deste gesto novo que consiste em interrogar as condiçóes históricas de nossas maneiras de dizer, de ver e de agir no mundo. (Ibid., p. 7-8)

Inicialmente apresentada praticamente como sinônimo de condiçôes históricas e de epistemê, a noção de configuração é recorrente ao longo das duas partes do livro, tanto aquela dedicada a Foucault quanto a dedicada a Merleau-Ponty. Algumas vezes vem acompanhada de qualificaçôes, como nos seguintes exemplos: "configuração contextual” (Ibid., p. 14-15); "configuraçôes epistêmicas" (Ibid., p. 74); "configuração histórica” (Ibid., p. 90); "configuração específica do nosso pensamento" (Ibid., p. 99); "configuração móvel" (Ibid., p. 109); "configuraçóes possíveis" (Ibid., p. 188); "configuraçôes eventuais" (Ibid.); "configurações mutáveis, mistas" (Ibid., p. 191-192).

Além desta, podemos identificar, no livro de J. Revel, a recorrência de outras noçóes bastante significativas, tanto em Merleau-Ponty quanto em Foucault, tais como: "paradoxo" (Ibid., p. 8, 71, 165, 170, 187, 199); "compossibilidade” e "copresença" (Ibid., pp. 12, 55, 152, 157, 183, 186); "entrelaçamento", "interstício", "entredois" (Ibid., p. 11, 150, 204); “vai-e-vem” e "zigue-zague” (Ibid., p. 11, 62, 153; 204); "entrecruzamento" e "cruzamento" (Ibid., p. 11, 165).

Não é difícil compreender que estas noçóes delineiam um traço comum que aproxima os dois pensadores: a irredutível duplicidade de faces, a simultaneidade de opostos, o desmantelamento de alternativas fáceis para falsas dicotomias. Sem pretender negligenciar as muitas diferenças certamente existentes, é, contudo, este traço que, em ambos, comanda as relaçóes entre a reflexão filosófica e os saberes das chamadas ciências humanas. Neste âmbito, o caso da história é particularmente destacável.

\section{A história}

É na convivência de pares opostos que se constrói a realidade da história. Ela transcorre na convergência e no embate entre a lógica e a contingência, o inteligível e o aleatório, o objetivo e o arbitrário, o dentro e o fora, o sentido e o não-sentido, a razão e a desrazão. Ou, se quisermos, ela acontece no jogo inacabável entre a 
"história já feita" e a "história se fazendo" ou "história em curso" (Revel, 2015, p. 13, 17; 141, 143, 155), a "acumulação do passado" e a "invenção do presente" (Ibid., p. 192, 206), a "sedimentaçáo" e a "novidade" (Ibid., p. 106, 199). Não se trata de conciliar opostos nem de optar entre eles, mas de manter sua tensão. O que está em consideração não é, escreve Revel, uma "falsa alternativa" entre "os efeitos de determinação da história, por um lado, ou da liberdade na história, por outro" (Ibid., p. 12, 207). Está em consideração uma “outra história” (Ibid., p. 209):

Ora, precisamente, a outra história que acreditamos reconhecer em Foucault como em Merleau-Ponty (é) uma representação da história que recusa escolher um dos dois lados da alternativa, sem, contudo, renunciar ao problema. A outra história (é) uma concepção de história que afirma a necessidade de pensar em conjunto, de maneira ao mesmo tempo indissociável e simultânea, as determinações e a liberdade, a história já feita e a abertura do presente, o assujeitamento e a subjetivação, o 'já-aí' do mundo e sua prosa - em suma, o estado presente das coisas e a 'diferença possível’” (Ibid., p. 209).

Se é esta a realidade da história, então a concepção filosófica da história, isto é, o pensamento da história, assim como o resultado da investigação histórica, isto é, a historiografia, se rigorosos e confiáveis, devem apreendê-la a como ela é, com seus paradoxos e copossibilidades, seus entrelaçamentos e interstícios, seus zigue-zagues e cruzamentos.

\section{IV. À guisa de conclusão}

O título do livro de J. Revel não traz e nem ou. A partícula usada é com: Foucault com Merleau-Ponty. Não porque os reduza um ao outro, mas certamente porque seu foco principal é a "representação 'em quiasma' nos dois filósofos, a partir de contextos e de referências sem dúvida muito diferentes" (Ibid.). Para exemplificar, algumas passagens bastante incisivas:

1) Sobre Merleau-Ponty em seus últimos anos: "uma espantosa antecipação de certos temas que Foucault desenvolverá vinte anos mais tarde” (Ibid., p. 133);

2) Sobre Merleau-Ponty dos anos 50: "a antecipação de toda uma série de motivos que reencontraremos mais tarde, por exemplo, em Foucault, sob a forma de uma tentativa para pensar conjuntamente a historicidade e a liberdade dos homens, as determinaçóes históricas e a 'diferença possível'” (Ibid., p. 122); e ainda: "encontramos em Merleau-Ponty a antecipação inesperada, quinze anos mais tarde em Foucault...” (Ibid., p. 123); 
3) Sobre a remissão recíproca entre as determinações históricas e a invenção da diferença na história: Merleau-Ponty "antecipa de modo notável a maneira como Foucault, quase vinte anos mais tarde, pensará o poder e a liberdade dos homens" (Ibid., p. 185);

4) Sobre a multiplicação das configurações possíveis da história e a noção de instituição em Merleau-Ponty, particularmente em relação à literatura: "Espantosamente, a ideia de Merleau-Ponty parece antecipar o que Foucault, comentando seu trabalho sobre Raymond Roussel, formulará sete anos mais tarde"; "o paralelismo das argumentaçôes concernentes à história e à literatura, de um filósofo ao outro, é perturbador (Ibid., p. 188, nota 3).

A par de tais aproximaçóes, não há que se negar ou desmerecer as distinçôes entre os dois filósofos. Mas há que se realçar pelo menos uma diferença, que é, ao mesmo tempo, uma complementariedade. Se Merleau-Ponty pretendeu mostrar a imprescindível reciprocidade entre a atividade do historiador e a tarefa do filósofo, Foucault reúne, numa mesma atividade, a investigação histórica - o trabalho historiográfico do arquivo - e a reflexão filosófica. Se Merleau-Ponty pensa filosoficamente sobre a história, Foucault investe a reflexão filosófica na prática da história. E se em ambos trata-se do "trabalho da história no coração da filosofia" (Ibid., p. 91), é porque se trata também do trabalho da filosofia no coração da história.

\section{Referências bibliográficas}

Merleau-Ponty, M. (1973). Ciências do homem e fenomenologia. Tradução, prefácio e notas de S. T. Muchail. São Paulo: Saraiva.

(1980). “O Metafísico no homem”. In: Merleau-Ponty, Textos Selecionados. Tradução e notas de M.de S. Chauí. Coleção Os Pensadores. São Paulo: Abril Cultural.

Foucault, M. (1981) As Palavras e as coisas. Tradução de S. T. Muchail. São Paulo: Martins Fontes.

Revel, J. (2015). Foucault avec Merleau-Ponty. Ontologie politique, présentisme et histroire. Coll. Philosophie du présent. Paris: Vrin. 